Running head: Employment and volunteering

Employment and Volunteering for Adults with Intellectual Disability

David Trembath

The University of Sydney

Susan Balandin

Høgskolen i Molde

Roger J Stancliffe

The University of Sydney

Leanne Togher

The University of Sydney

Key words: Volunteer, paid work, intellectual disability, participation, competitive employment 


\begin{abstract}
Issues: Employment is a fundamental part of adult life. However, adults with intellectual disability (ID) face multiple barriers to employment and are underrepresented in the paid workforce. Formal volunteering has been promoted as both a stepping stone, and alternative, to employment for some adults with disability. The purpose of this brief report is to provide an overview of research findings relating to volunteering and employment for adults with ID. Findings: Few studies have examined the experiences of adults with ID who volunteer. The limited findings indicate that volunteering alone is unlikely to lead to employment for adults with ID. However, some adults with ID view volunteering as a meaningful and desirable alternative to paid work.

Conclusions: There is a need for further research to examine the relationship between volunteering and employment for adults with ID. In addition, there is a need for practice guidelines to ensure that the outcomes for adults with ID who volunteer, and those who seek employment, are successful.
\end{abstract}




\section{Employment and Volunteering for Adults with Intellectual Disability}

Employment is a fundamental part of adult life and a goal to which adults with and without disability aspire (Jahoda, Kemp, Riddell, \& Banks, 2008). The benefits of work for those who are employed include greater autonomy and financial freedom (Jahoda, et al., 2008), increased self-esteem and emotional well being (Stevens \& Martin, 1999; Winn \& Hay, 2009), and improved quality of life (Lemaire \& Mallik, 2008; Martorell, Gutierrez-Recacha, Pereda, \& Ayuso-Mateos, 2008). Employment also confers social status and leads to increased social networks, both within and outside the workplace (Grant, 2008; Jahoda, et al., 2008). However, not all adults have access to competitive employment, as referred to in this article, and the ensuing benefits. In particular, adults with intellectual disability (ID) face multiple barriers to employment and are underrepresented in the paid workforce (Grant, 2008; Lemaire \& Mallik, 2008; Verdonschot, Witte, Reichrath, Buntinx, \& Curfs, 2009).

\section{Barriers to employment}

According to Shier, Grahan, and Jones (2009), adults with ID face both internal and external barriers to employment. Internal barriers can include a lack of motivation or selfconfidence (Winn \& Hay, 2009), inadequate work experience (Winn \& Hay, 2009), low levels of literacy and numeracy (Winn \& Hay, 2009), the presence of challenging behaviour (Lemaire \& Mallik, 2008; Martorell, et al., 2008), and difficulties understanding unwritten workplace rules (Jahoda, et al., 2008). External barriers that may also impact negatively on employment include a lack of job opportunities (Grant, 2008), a lack of appropriate support (Shier, et al., 2009), and discrimination and stigmatisation in the workplace (Butcher \& Wilton, 2008; Winn \& Hay, 2009). Many adults with ID require support to overcome these barriers in order to gain employment. Others may never be employed and so require meaningful and desirable 
alternatives to paid work (Butcher \& Wilton, 2008). Volunteering may provide both meaningful activity and the opportunity for increased community participation.

\section{Volunteering}

Formal volunteering has been promoted as both a stepping stone, and alternative, to employment for adults with disability (Held \& Granholm, 2007; Mencap, 2009a). Defined as an activity which takes place in not for profit organisations, of an individual's own free will, and in positions that do not replace the need for paid workers (Volunteering Australia, 2005), formal volunteering has been shown to result in a number of benefits for individuals with ID. Miller et al. (2002), for example, reported that a 20-week volunteering program led to increases in pride, empowerment, social interactions, and verbal communication amongst 10 adolescent students with ID who participated. Similarly, Balandin, Llewellyn, Dew, Ballin, and Schneider (2006), reported that volunteering resulted in the development of knowledge, skills, and social networks among 14 adults with longstanding disability, including four with ID. However, despite the common perception that volunteering is a route to paid work (Held \& Granholm, 2007), little is known about the effect volunteering has on the employment prospects of adults with ID.

\section{Volunteering as a stepping stone to paid work}

Despite the lack of specific research evidence concerning adults with ID, governments (e.g., Australian Government, 2009), peak volunteering bodies (e.g., Institute for Volunteering Research, 2009), disability service providers (e.g., Mencap, 2009a), and researchers (e.g., Held \& Granholm, 2007) have all proposed a link between volunteering and paid work. Held and Granholm (2007) suggested that the benefits that come from volunteering, such as the development of new skills and increased self esteem, improve the employment prospects of those looking for paid work. Mencap, identified work experience, which may be gained through 
volunteering, as the key outcome for adults with ID seeking paid work (Mencap, 2009b). To date, the distinction between volunteering and work experience has not been made in the volunteering literature relating to adults with disability. Although work experience is a highly regarded element of many supported employment programs (e.g., Jobsupport, 2008; Mencap, 2009b), it cannot be considered to be volunteering if it is an obligatory part of an employment program or if the volunteers fulfill roles that would otherwise be occupied by paid staff (Volunteering Australia, 2006).

In one of the few studies examining the relationship between volunteering and paid work for adults with disability, Reilly (2005, pp. 8-9), for example, interviewed “...over 100 individual volunteers..." who "...defined themselves as disabled..." regarding their experiences of volunteering. According to Reilly, some participants indicated that volunteering had improved their prospects for employment. However, it is not clear how many participants expressed this view and how many went on to gain paid work. Hirst (2001) surveyed 1,911 adults who accessed employment services in the UK over an 11 month period. Sixteen percent of the group identified as having disability. Although $88 \%$ of those seeking employment believed that volunteering would improve their job prospects, only $41 \%$ of those who gained paid work believed that volunteering had helped them achieve this outcome (Hirst, 2001). Hirst concluded that although volunteering resulted in a range of benefits for the participants, there was no discernable difference in employment outcomes between those who did and did not volunteer. In fact, Hirst noted that those who volunteered took longer to gain employment than those who did not volunteer. These findings cast doubt on the notion that volunteering in itself provides a stepping stone to paid work for adults with ID. 
The results of a recent study by Trembath, Balandin, Stancliffe, and Togher (2009) also question the notion of a direct link between volunteering and employment for adults with disability more broadly. Trembath and colleagues examined the experiences of 24 adults with longstanding physical disability and complex communication needs who engaged in volunteering. Although the participants believed that volunteering could improve their employment prospects, only three volunteered in an attempt to gain paid work, and only one participant was successful. Based on these findings, Trembath and colleagues suggested that volunteering alone is unlikely to lead to employment for adults with disability. They proposed that those seeking paid work might be more successful if they utilised dedicated employment programs. Nevertheless, Trembath et al. affirmed the findings of previous studies, identifying a range of benefits that came from volunteering. These benefits included the development of knowledge and skills (Balandin, et al., 2006; Choma \& Ochocka, 2005; Reilly, 2005), increased self-esteem and confidence (Choma \& Ochocka, 2005; Reilly, 2005; Simpson, 2001), and expansion of their social networks (Balandin, et al., 2006; Choma \& Ochocka, 2005; Reilly, 2005). Furthermore, the authors also identified that volunteering provided meaningful occupation as an alternative to employment to some adults with disability.

\section{Volunteering as an alternative to paid work}

Trembath et al. (2009) reported that three participants with longstanding disability, who were unable work due to the severity of their disability, volunteered in order to take on a meaningful work-like activity. Indeed, these adults described their volunteering as their 'work,' albeit unpaid, highlighting the status and sense of occupation their voluntary work provided. Like work, volunteering provided the participants with an opportunity to develop their knowledge and skills, increase their social networks, and improve their quality of life (Trembath, 
Balandin, Stancliffe, et al., 2009). Furthermore, volunteering enabled the participants to be providers, rather than recipients of community service (Trembath, Balandin, Togher, \& Stancliffe, 2009). Butcher and Wilton (2008) argued that the notion of gainful employment and community participation must be broadened to recognise a variety of meaningful societal roles, including volunteering. Although limited, the evidence to date suggests that some adults with disability do see volunteering as not only meaningful activity but also a desirable work-like alternative to employment.

Bates (2002) presented anecdotal reports that adults with ID may initially choose volunteering over employment for a number of reasons. Specifically, Bates noted that volunteering may help adults with ID identify the type of work they would like to pursue and that volunteering may fit more easily around family responsibilities or part-time study. However, the criteria for those most likely to benefit from the volunteering rather than work experience are not clear, nor is it known under what circumstances people with ID should be encouraged to volunteer as an alternative to seeking paid work. In addition, there are concerns that although volunteering can provide a meaningful alternative to paid work, adults with ID who volunteer may be at risk of exploitation (Roker, Player, \& Coleman, 1998).

Roker, Player, and Coleman (1998) conducted a national survey of volunteering by young adults with disability. The authors raised concerns that many young adults with ID described their volunteering as their work, and did not appear to distinguish between the two roles. Therefore, some individuals with ID may agree to volunteer without realising, or learning about their options for employment. In addition, Roker and colleagues suggested that if adults with ID are content in their volunteering roles and unaware of alternative forms of employment, then family members and support staff who might otherwise support their transition to 
employment may become complacent and fail to do so. Thus, it is important to ensure that adults with ID who volunteer are aware of the employment options available to them in order to reduce the risk of exploitation. Furthermore, it is imperative that staff in organisations that utilise and support adults with ID who volunteer, carefully assess the motivations of each individual in order to distinguish between those who want to volunteer and those who are ultimately seeking paid work (Trembath, Balandin, Stancliffe, et al., 2009).

\section{Implications for practice}

The findings of research to date, though limited, have several key implications for practice. Many adults with ID volunteer for the benefits volunteering brings to their own lives and the lives of others, irrespective of whether or not they are seeking employment (Balandin, et al., 2006). In addition, it is clear that some adults with physical disability view volunteering as a meaningful alternative to paid work and have a real sense of occupation (Trembath, Balandin, Stancliffe, et al., 2009), and the same may be true for some adults with ID. Therefore, adults with ID should have access to the same volunteering opportunities as their peers without disability along with the support they require in order to volunteer successfully (Butcher \& Wilton, 2008). However, the situation becomes more complex in cases where adults with ID (a) are encouraged to volunteer in an attempt to improve their employment prospects or (b) volunteer without knowing, or being made aware of, their options for employment. There is a need for research to examine these issues to inform the development of practice guidelines for volunteering and employment for adults with ID.

Volunteering, by definition, is undertaken of an individual's own free will and without obligation or coercion (Volunteering Australia, 2005). It is imperative that adults with ID who volunteer do so willingly and knowingly, with a clear understanding of the nature of their 
volunteering roles. To this end, volunteer agencies and supported employment programs alike must clearly differentiate between situations in which adults with ID are offered the opportunity to volunteer and situations in which they are required to complete work experience as part of an employment program. Furthermore, the purpose and likely outcomes of the practical experiences provided by these programs must be clearly articulated. Based on the limited research to date, volunteering alone appears unlikely to lead to employment for most people with disability (Trembath, Balandin, Stancliffe, et al., 2009). Therefore, adults with ID who are seeking paid work may be best served by engaging in work experience as part of a dedicated employment program, rather than engaging in more general volunteering roles.

The issue of ensuring that adults with ID are able to make informed decisions regarding volunteering is often complicated. There are, as yet, no guidelines to inform the decision making process. Consequently, family members and staff who support people with ID in decision making must base their decisions on two fundamental principles. First, adults with ID have the right to participate in, and choose between, paid work, voluntary work, and work experience (Mencap, 2009c). Family members and staff need to explore and present all three options to adults with ID. Second, motivation is the key to successful volunteering. Family members and staff may need to consider the individual motivations of each individual, and the extent to which volunteering addresses these motivations. In situations where it is not possible to distinguish between an individual's preference and motivations for volunteering and paid work, ideally both options should be pursued.

\section{Conclusion}

Although there has been a strong research focus on employment for adults with ID in recent years, few studies have examined the merits of volunteering. This is despite the fact that 
volunteering is popular and highly valued in society (International Association for Volunteer Effort, 2001), and promoted as a stepping stone to employment for adults with and without disability (Held, 2007; Institute for Volunteering Research, 2009). Although volunteering may provide some adults with ID with meaningful and enjoyable activity (Bates, 2002) there is little evidence to suggest that volunteering alone leads to employment for adults with ID. However, work experience, undertaken as part of a dedicated employment program, is a common element of supported employment programs and may improve the employment prospects of adults with ID.

Further research is needed to examine the relationship between volunteering and employment for adults with ID. Qualitative studies could examine the experiences and views of adults with ID who have and have not volunteered and the extent to which they see volunteering as a stepping stone towards employment. Quantitative studies could examine the outcomes for adults with ID who volunteer in order to gain paid work, including the rate of success and the factors which influence the likelihood of a successful outcome. The findings of such research would help to inform the development of practice guidelines which are needed to ensure that both volunteering and employment opportunities are available to adults with ID and to assist them to make informed choices and to achieve their chosen goals 


\section{References}

Australian Government (2009). Work Experience: Voluntary Work. Canberra: Job Services Australia.

Balandin, S., Llewellyn, G., Dew, A., Ballin, L., \& Schneider, J. (2006). Older disabled workers' perceptions of volunteering. Disability \& Society, 21(7), 677-692.

Bates, P. (2002). A real asset: A manual on supported volunteering. Bath: National Development Team for Inclusion.

Butcher, S., \& Wilton, R. (2008). Stuck in transition? Exploring the spaces of employment training for youth with intellectual disability. Geoforum, 39, 1079-1092.

Choma, B. L., \& Ochocka, J. (2005). Supported volunteering: A community approach for people with complex needs. Journal on Developmental Disabilities, 12(1), 1-18.

Grant, J. (2008). Paid work - A valued social role that is empowering more people with an intellectual disability and providing employers with dedicated employees! Journal of Intellectual \& Developmental Disability, 33(1), 95-97.

Held, M. (2007). CEV Contribution to the Draft Report on the role of volunteering in contributing to economic and social cohesion: European Volunteer Centre.

Held, M., \& Granholm, P. (2007). Volunteering as a route (back) to employment: Executive Summary. Paris: European Volunteer Centre.

Hirst, A. (2001). Links between Volunteering and Employability (report number RR309). London: Department for Education and Skills.

Institute for Volunteering Research (2009). The benefits of volunteering for employability - key findings from recent research by The Institute for Volunteering Research Retrieved 26/06/09, 2009, from 
http://www.ivr.org.uk/researchbulletins/The+benefits+of+volunteering+for+employabilit $\mathrm{y}+\% \mathrm{E} 2 \% 80 \% 93+$ key+findings+from+recent+research+by+The+Institute.htm.

International Association for Volunteer Effort (2001). Universal Declaration on Volunteering. Amsterdam: International Association for Volunteer Effort.

Jahoda, A., Kemp, J., Riddell, S., \& Banks, P. (2008). Feelings about work: A review of the socio-emotional impact of supported employment on people with intellectual disabilities. Journal of Applied Research in Intellectual Disabilities, 21(1), 1-18.

Jobsupport (2008). Transition to work: Community work options Retrieved 15/07/09, 2009, from http://www.jobsupport.org.au/main/content/view/19/36/.

Lemaire, G. S., \& Mallik, K. (2008). Barriers to supported employment for persons with developmental disabilities. Archives of Psychiatric Nursing, 22(3), 147-155.

Martorell, A., Gutierrez-Recacha, P., Pereda, A., \& Ayuso-Mateos, J. L. (2008). Identification of personal factors that determine work outcome for adults with intellectual disability. Journal of Intellectual Disability Research, 52, 1091-1101.

Mencap (2009a). Finding a Job Retrieved 26/06/09, 2009, from http://www.mencap.org.uk/page.asp?id=167.

Mencap (2009b). Mencap Advcance: Preparing for work Retrieved 30/07/09, 2009, from http://www.mencap.org.uk/page.asp?id=1524.

Mencap (2009c). Mencap Charter of Employment Rights Retrieved 15/07/09, 2009, from http://uk.sitestat.com/mencap/mencap/s?resources.publications.mencap_charter_of_empl oyment_rights.269.download\&ns_type=pdf\&ns_url=http://www.mencap.org.uk/displayp agedoc. asp ?id=269. 
Miller, K. D., Schleien, S. J., Rider, C., Hall, C., Roche, M., \& Worsley, J. (2002). Inclusive volunteering: Benefits to participants and the community. Therapeutic Recreation Journal, 36, 247-259.

Reilly, C. (2005). Volunteering and disability: Experiences and perceptions of volunteering from disabled people and organisations. Stirling, Scotland: Volunteer Development Scotland.

Roker, D., Player, K., \& Coleman, J. (1998). Challenging the image: the involvement of young people with disabilities in volunteering and campaigning. Disability \& Society, 13(5), $725-741$.

Shier, M., Graham, J. R., \& Jones, M. E. (2009). Barriers to employment as experienced by disabled people: a qualitative analysis in Calgary and Regina, Canada. Disability \& Society, 24(1), 63-75.

Simpson, M. (2001). Involvement of People with Disabilities: Myth versus reality. Australian Journal on Volunteering, 6, 2.

Stevens, P., \& Martin, N. (1999). Supporting individuals with intellectual disability and challenging behaviour in integrated work settings: an overview and a model for service provision. Journal of Intellectual Disability Research, 43, 19-29.

Trembath, D., Balandin, S., Stancliffe, R. J., \& Togher, L. (2009). Volunteering and paid work for adults who use AAC (submitted).

Trembath, D., Balandin, S., Togher, L., \& Stancliffe, R. J. (2009). The experiences of adults with complex communication needs who volunteer (submitted).

Verdonschot, M. M. L., Witte, L. P. d., Reichrath, E., Buntinx, W. H. E., \& Curfs, L. M. G. (2009). Community participation of people with an intellectual disability: a review of empirical findings. Journal of Intellectual Disability Research, 53(4), 303-318. 
Volunteering Australia (2005). Definitions and Principles of Volunteering. Melbourne:

Volunteering Australia.

Volunteering Australia (2006). The principles of volunteering: Why have them? Retrieved 12/07/09, 2009, from

http://www.volunteeringaustralia.org/files/E0EZLOSW05/The_Intent_of_the_Principles_ of_Volunteering.pdf.

Winn, S., \& Hay, I. (2009). Transition from school for youths with a disability: issues and challenges. Disability \& Society, 24(1), 103-115. 


\section{Author Note}

David Trembath, Discipline of Speech Pathology, University of Sydney; Susan Balandin, Avdeling for helse- og sosialfag Høgskolen i Molde; Roger Stancliffe, Discipline of Occupational Therapy, University of Sydney; Leanne Togher, Discipline of Speech Pathology, University of Sydney.

David Trembath is now at the Olga Tennison Autism Research Centre, School of Psychological Science, La Trobe University.

This research formed part of David Trembath's Ph.D. thesis and was supported by a National Health and Medical Research Council postgraduate research scholarship.

Correspondence concerning this article should be addressed to David Trembath, Olga

Tennison Autism Research Centre, School of Psychological Science, La Trobe University, Bundoora VIC 3086, Australia. E-mail: D.Trembath@1atrobe.edu.au 